\title{
Prolactinoma Male Patient with Clinical Manifestations of Hypopituitarism and Gynecomastia
}

\author{
Yudith Annisa Ayu Rezkitha ${ }^{1,2,3}$, Hermina Novida ${ }^{1}$, Soebagijo Adi $^{1}$, Agung Pranoto ${ }^{1}$ and Ari \\ Sutjahjo \\ ${ }^{I}$ Department of Internal Medicine, Faculty of Medicine, Universitas Airlangga, Dr. Soetomo General Hospital, Surabaya, \\ Indonesia \\ ${ }^{2}$ Institude of Tropical Disease, Universitas Airlangga, C Campus, Jalan Mulyorejo, Gubeng, Surabaya 60286, Indonesia \\ ${ }^{3}$ Faculty of Medicine, Universitas Muhammadiyah Surabaya, Jl. Raya Sutorejo no.59, Dukuh Sutorejo, Mulyorejo, \\ Surabaya 60113, Indonesia \\ apji@fk.unair.ac.id
}

Keywords: Ginekomasti, Hypopituitari, Pituitary, Prolactin, Prolactinoma.

\begin{abstract}
Prolactinomas are the most common benign neoplasms (about 40\%) among pituitary tumors. The definitive diagnosis of prolactinomas is quite difficult and almost all cases require additional checks of prolactin levels, radioimmunoassay, Computerized Tomography scan and Magnetic Resonance Imaging. Prolactinomas may cause some symptoms related to hormonal effects due to excess prolactin and spaceoccupying effects of the tumor itself. Prolactinoma develops slowly and clinically depends on age, sex, duration, and degree of hyperprolactinemia. Gynecomastia is a benign tumor characterized by breast enlargement in males caused by the proliferation of glandular tissue and local fat deposition. This is a report of a 43 year old man complaining of having blurry eyes, headache, decreased libido and breast growth. Hormonal examination found an increase in prolactin level accompanied by secondary hypocortisol and secondary hypothyroid. From the examination, Multi Slice Computed Tomography found a macroprolactinoma. Surgery was performed using the transsphenoidal technique with $5 \mathrm{mg}$ of Prednisone twice a day orally, $50 \mathrm{mcg}$ of Euthyrox once a day orally and Bromocriptine with a dose of $2.5 \mathrm{mg}$. One month postoperative there was elimination of headache complaints, vision improved and breasts diminished even though libido had not returned. Prolactin levels returned to normal but there was still hypothyroid and hypocritical with a good prognosis with regular taking of hormone replacement drugs.
\end{abstract}

\section{INTRODUCTION}

Prolactinomas are the most common benign neoplasms among pituitary tumors accounting for $40 \%$ of all pituitary tumors. Prolactinoma consists of Laktrotrop which secretes excess prolactin at various levels to produce hyperprolactinemia. Normal prolactin level in women is under $25 \mathrm{ng} / \mathrm{mL}$ and men under $20 \mathrm{ng} / \mathrm{mL}$ (Nassiri, 2012). In the prolactinoma state, it can reach levels up to > $100 \mathrm{ug} / \mathrm{L}$ (Melmed, 2005).

The definitive diagnosis of prolactinomas is quite difficult and almost all cases require additional checks of prolactin levels, radioimmunoassay, Computized Tomography scan (CT-scan) and Magnetic Resonance Imaging (MRI) (Levin, 2001; Gandhi, 2003). Prolactinomas might cause some symptoms related to hormonal effects due to excess prolactin and space-occupying effects of the tumor itself. Prolactinoma develops slowly and clinical features depend on age, sex, duration, and degree of hyperprolactinemia (Gandhi, 2003; Salazar-LopezOrtiz et al., 2014). In men, the main complaint is usually associated with hypogonadism, namely decreased libido, erectile dysfunction, and gynecomastia.

Gynecomastia is a benign tumor characterized by breast enlargement in males caused by the proliferation of glandular tissue and local fat deposition. Unlike the pathophysiology of gynecological occurrence due to other causes, in patients with prolactinoma prolactin receptors are found in gynecomastia. In addition, the condition of hyperprolactinemia might have an indirect effect on the occurrence of gynecomastia, the influence of central hypogonadism and changes in the 
androgen/estrogen ratio. However, almost all men with gynecomastia have no increase in the hormone prolactin, and not all men with hyperprolactinemia have gynecomastia. There is suspected coexpression and cross-regulation between prolactin and progesterone receptors and estrogen activation through Insulin-Like Growth Factor-1 (IGF-1) receptors (Barros and Sampaio Mde, 2012).

Prolactinoma therapy aims to reduce prolactin concentrations and clinical consequences, such as gonadal dysfunction, infertility, and osteoporosis as well as reduction of tumor mass, thus eliminating field defects and hypopituitarism; retained pituitary rest function; prevention of the sustained growth of tumor mass, and improved quality of life. Currently, there are three methods of therapy for prolactinoma, namely medical therapy with dopamine agonists, surgical therapy using a transsphenoidal or transcranial approach and external radiation (Katznelson, 2002; Gandhi, 2003). The following is the case of a male patient with prolactinoma accompanied by hypopituitarism clinical manifestations and gynecomastia.

\section{CASE}

Mr. J, aged 43, Javanese, S1, Entrepreneur, living in Tuban, on January 8, 2014, came to the Emergency unit of Dr. Soetomo General Hospital, Surabaya. The main complaint of the patient was poor eyesight.

Anamnesis and physical examination. The vision of the left eye began to diminish since one year ago. Initially the patient was able to see the whole view, but the longer the vision of the left eye looked dark beside the outer edge and increasingly heavy to dark in the middle. The left eye was unable see at all, while the right eye started experiencing the same complaint that looks dark when looking sideways. There were no eye pain or red eye complaints. The patient also complained of sharp pain all over the head but not pulsed, which disappeared a year ago. There was no nausea, vomiting, fever or seizures. There was no body paralysis or tingling sensation in the body.

Since six months before, the patient also felt the growth of his breasts accompanied by decreased libido. The patient also complained of hair body thinning, ease to feel tired and not strong against the cold. There were no difficulties of diarrhea, joint and muscle pain, hoarseness or weight loss.

There was no history of diabetes, high blood pressure, jaundice or consumption of drugs such as anti-vomiting drugs, high blood pressure medicine, and psychiatric drugs. The patient had been married for 20 years without previous sexual dysfunction and had two children.

A physical examination found Glagsow Coma Scale (GCS) 456, Blood pressure 100/70 $\mathrm{mmHg}$, pulse $70 \mathrm{x} / \mathrm{m}$, respiration rate 20 times every minute, temperature $36^{\circ} \mathrm{C}$. Head and neck had no anemia, jaundice, cyanosis, or dyspnea. Jugularis Venous Pressure (JVP) did not increase and no enlarged struma or lymph nodes were observed. Chest examination found symmetric breast enlargement, with a diameter of $10 \mathrm{~cm}$ concentric, rubbery, firm but not hard, no local mass or pupil retention, no galactorrhoea and a thin armpit. Additionally, there was also no spider nevi or collateral veins found, the single of the first (S1) and second heart sound (S2), and no murmur or gallop. There were vesicular lung sounds in both lung fields. Abdominal examination found no striae or ascites, hepar and lien were not palpable and also bowel sounds were normal. Examination of the extremities found a warm red dry aural, without edema and palmar erythema with large testis and of normal form. Based on the neurological status, there was decrease of Oculo Dextro (OD) 1/60 and Oculo Sininstro (OS) (-) visions and fundoscopy showed Oculo Dextro Et Sinistro (ODS) of atrophic pupil and field narrowing.

Laboratory examination recorded hemoglobin $11.1 \mathrm{~g} / \mathrm{dl}$, leukocytes $10,400 / \mathrm{uL}$, platelet count 370,000/uL, Hematocrit 30\%, Serum Glutamic Oxaloacetic Transaminase (SGOT) 17/uL, Serum Glutamic Piruvic Transaminase (SGPT) 8.7/uL, albumin $3.78 \mathrm{gr} / \mathrm{dl}$, Bun $7.1 \mathrm{mg} / \mathrm{dl}$, serum creatinine $0.69 \mathrm{mg} / \mathrm{dl}$, Random glucose $81 \mathrm{mg} / \mathrm{dl}$, sodium 146 $\mathrm{mEq} / \mathrm{L}$, potassium $3.7 \mathrm{mEq} / \mathrm{L}$, chloride $110 \mathrm{mEq} / \mathrm{L}$ and negative Hepatitis B surface Antigen ( $\mathrm{HbsAg}$ ). At the time of the patient's hospital admission he brought his laboratory results of one month before, which included Adrenocorticotropic Hormone (ACTH) $13 \mathrm{pg} / \mathrm{ml}(6-50 \mathrm{pg} / \mathrm{ml})$, cortisol < $10 \mathrm{ng} / \mathrm{ml}$ (morning 62-194, afternoon $23-119 \mathrm{ng} / \mathrm{ml}$ ), prolactin 33.07 (male: $1.5-1.9)$, Growth hormone $(\mathrm{GH})<0.05$ $\mathrm{ng} / \mathrm{ml}(0.06-5 \mathrm{ng} / \mathrm{ml})$.

Radiological examination showed a plain picture of the heart and lung-chest within normal limits. Multi Slice Computed Tomography (MSCT) scans the head scan showed a lobe-cystic caecal mass with firm borders, regular edges, $3.78 \times 3.27 \times 4.04 \mathrm{~cm}$ with the hypotheses that $\mathrm{T} 1$ was hypointense, and T2 was hypertensive, with contrast enhancement contrast. The mass appeared to extend to the suprasellar and suppress the optic chiasma. The 
diagnosis was pituitary cyst macroprolactinoma and rathke cleft cyst.

Based on anamnesis, physical and laboratory examination then diagnosed a suspected primary cerebral neoplasm, prolactinemia, and chronic cephalgia. Intervention planning: bed rest, infusion Ringer Lactat 14 drops every minute, three times a day of dexamethasone ampoules intravenously, and twice a day ranitidine ampoules intravenously. The patient was admitted to the hospital in Seruni A room. On the $4^{\text {th }}$ day, the patient was sent to internal medical science in the field of internal medicine, finding macroprolactinoma pituitary, hyperprolactinemia, and hypocortisol. Suggestion: please complete testosterone hormone, Thyroid Stimulating Hormone (TSH) and Free T4 (FT4) levels. Then, take $2.5 \mathrm{mg}$ of bromocryptine once a day orally and $5 \mathrm{mg}$ of Prednisone twice a day orally.

On the $13^{\text {rd }}$ day, the patient said his headache began to decrease, but vision was still blurred. GCS 456 , blood pressure $100 / 70 \mathrm{mmHg}$, pulse $70 \mathrm{x} / \mathrm{m}$, respiration rate 20 times every minute, temperature $36^{\circ} \mathrm{C}$. Laboratory examination recorded SGOT 32/uL, SGPT 47/uL, Albumin 3.8 gr/dl, Bun 20 $\mathrm{mg} / \mathrm{dl}$, creatinine serum $0.8 \mathrm{mg} / \mathrm{dl}$, Fasting Plasma Glucose 75 mg/dl, Post Randial Glucose 128 mg/dl Sodium $136 \mathrm{mEq} / \mathrm{L}$, Potassium $5 \mathrm{mEq} / \mathrm{L}$, chloride $99 \mathrm{mEq} / \mathrm{L}, \mathrm{TSH}<0.004 \mathrm{uIU} / \mathrm{ml}(0.35-5.50)$, FT4 $0.41 \mathrm{ng} / \mathrm{dl}(0.89-1.76)$, total T3 $0.19 \mathrm{ug} / \mathrm{dl}(0.60-$ $1.81)$, total T4 $8.4 \mathrm{ug} / \mathrm{dl}$ (4.50-10.90).

The diagnosis was macroprolactinoma pituitary, hyperprolactinemia, hipocortisol, and hypothyroid. Suggestions: $2.5 \mathrm{mg}$ of Bromocryptine once a day orally, $5 \mathrm{mg}$ of Prednisone twice a day orally continuously, and $50 \mathrm{mcg}$ of Euthyrox once a day oral and to consult a neurosurgeon for surgical consideration. Neurosurgeon diagnosed the patient with macroprolactinoma pituitary and suggested for excising the tumor.

On the $20^{\text {th }}$ day the patient said his headache began to decrease, but vision was still blurred. Examination found GCS 456, blood pressure 110/70 $\mathrm{mmHg}$, pulse $80 \mathrm{x} / \mathrm{m}$, respiration rate 20 times every minute, temperature $36^{\circ} \mathrm{C}$. Laboratory test found TSH $0.37 \mathrm{uIU} / \mathrm{ml}(0.35-5.50)$, FT4 $0.56 \mathrm{ng} / \mathrm{dl}(0.89-$ 1.76), T3 total $0.52 \mathrm{ug} / \mathrm{dl}(0.60-1.81)$, T4 total of 7.2 ug/dl (4.50-10.90). Therapy: $2.5 \mathrm{mg}$ of Bromocryptine once a day orally, $5 \mathrm{mg}$ of Prednisone twice a day orally, $50 \mathrm{mcg}$ of Euthyrox once a day orally to continue while waiting for the surgical plan of neurosurgery.

On the $37^{\text {th }}$ day tumor resection surgery was performed using the transsphenoidal technique.
After the operation, the patient was well aware with no headache. Vision still had no change. Physical examination found GCS 456 blood pressure $110 / 80 \mathrm{mmHg}$, pulse $88 \mathrm{x} / \mathrm{m}$, respiration rate 20 times every minute, temperature $37^{\circ} \mathrm{C}$. Laboratory examination post operation found $\mathrm{Hb} 11 \mathrm{~g} / \mathrm{dl}$, leukocytes 19,600/uL, platelets 437,000/uL, albumin $3.92 \mathrm{gr} / \mathrm{dl}$, Bun $6.7 \mathrm{mg} / \mathrm{dl}$, serum creatinine 0.66 $\mathrm{mg} / \mathrm{dl}$, GDA $216 \mathrm{mg} / \mathrm{dl}$, sodium $138.5 \mathrm{mEq} / \mathrm{L}$, potassium $3.98 \mathrm{mEq} / \mathrm{L}$, chloride $108 \mathrm{mEq} / \mathrm{L}$.

Therapy from internal disease: examination of cortisol, TSH, and FT4 postoperatively. The patient was given stress dose steroid pre-op and post-op with $2 \mathrm{mg}$ of dexamethasone intravenous. Prednisone therapy was $5 \mathrm{mg}$ twice a day orally and $50 \mathrm{mcg}$ of Euthyrox once a day orally was still given.

On the $41^{\text {st }}$ day/Day 3 post-op, PA result was prolactinoma so the patient planned leave the hospital for monitoring in the endocrine unit. The patient requested laboratory tests through the unit. Drugs taken home were $5 \mathrm{mg}$ of Prednisone twice a day orally and $50 \mathrm{mcg}$ of Euthyrox once a day orally.

One month after discharge from the hospital, the patients came to the endocrine unit, saying that a headache did not exist, but the left eye was still unable to see, but the right eye had started to improve. A dead-end or often runny nose was absent. Libido had not returned yet, but the breasts had started to look smaller. Physical examination found GCS 456 blood pressure 100/70 $\mathrm{mmHg}$, Pulse $84 \mathrm{x} / \mathrm{m}$, respiration rate 20 times per minute, temperature $36^{\circ} \mathrm{C}$. The plan was laboratory prolactin, Luteneizing Hormone (LH), testosterone, cortisol, TSH, and FT4 with $5 \mathrm{mg}$ of Prednisone therapy twice a day orally and $50 \mathrm{mcg}$ of Euthyrox once a day orally.

Two months after discharge, the patient came back to the endocrine unit with laboratory results of cortisol $1.27 \mathrm{ng} / \mathrm{ml}$ (morning 62-194, afternoon 23$119 \mathrm{ng} / \mathrm{ml}$ ), prolactin 19.29 (men: 2,1-17,7), TSH $0.28 \mathrm{uIU} / \mathrm{ml}$ (0.35-5.50), FT4 $0.78 \mathrm{ng} / \mathrm{dl}(0.89-1.76)$. $\mathrm{LH}$ and testosterone examination were not performed.

\section{DISCUSSION}

The prevalence of prolactinoma in women (8.7 every 100,000 people) is recorded five times more than in men ( 1.4 every 100,000 people). The highest incidence is found in women in the 25-34 age range where women have more macroprolactinomas. 
Then, $60 \%$ of adult men with macroprolactinoma are diagnosed in their 40s (Kars et al., 2010).

The patient was a 43 year old male at the highest incidence of prolactinoma incidence. Although frequent clinical symptoms seen in patients with prolactinoma are gonadal and sexual dysfunction associated with hyperprolactinemia, in macroprolactinomas there are often neurologic manifestations of a headache, visual impairment from quadrantanopia to bitemporal hemianopia and scotoma due to suprasellar compression to optic chiasma (Kars et al., 2010). Headaches associated with tumor pituitary do not have any clinical characteristics, although Levy et al. describes painful piercing (27\%) and cluster headaches (9\%) (Benitez, 2009; Edvardsson, 2013).

In the patient the vision of the left eye began to decrease one year before which became more and more burdensome, followed by complaints in the right eye. There was no eye pain or red eye complaints. The patient also complained of nonspecific pain throughout the head but not pulsed and disappeared a year ago.

Hyperprolactinemia leads to hypogonadotropic hypogonadism in both men and women due to the suppressive effect stemming from an increase in the concentration of prolactin towards gonadotropinreleasing hormone $(\mathrm{GnRH})$. So the most common symptoms of hyperprolactinemia in premenopausal women are amenorrhea and galactorrhoea, whereas in men it there can be symptoms of impotence, decreased libido, decreased beard growth and gynecomastia associated with hyperprolactinemia (Kars et al., 2010; Ashrafuzzama, 2013). The patient had complaints of hair thinning all over the body since six months before. The patient also noticed the growth of breasts accompanied by decreased libido.

In general, gynecomastia occurs in the 9-29 age range, with varied causes, mostly due to idiopathic gynecomastia (58\%), while the rest are due to hypogonadism (25\%), hyperprolactinaemia $(9 \%)$, chronic liver disease (4\%), and due to drug addiction (4\%) (Johnson and Murad, 2009).

Gynecomastia can be distinguished by Pseudogynecomastia and breast cancer through physical examination. Gynecomastia is characterized by a soft, elastic, firm but not hard breast tissue. The affected area was concentrically dispersed over the papilla-areolar complex and largely bilateral. Pseudogynecomastia is characterized by increased subareolar fat without enlargement of breast gland components in the area. Breast carcinoma is usually hard, located outside the area of the papilla-areolar complex and often unilateral. In addition, skin and papilla retraction are not found in gynecomastia; however, it can be seen in patients with breast cancer. Galactorrhoea is a weak sign for predicting hyperprolactinemia because $50 \%$ of patients with galactorrhoea have normal serum prolactin (Wass, 2002; Katznelson, 2002). Hyperprolactinemia in prepuberty may cause a small female body and testicular stature (Salazar-Lopez-Ortiz et al., 2014).

This patient had symmetrical breast enlargement, concentric $10 \mathrm{~cm}$ diameter, rubbery, firm but not hard, and neither local mass nor papillary retention nor galactorrhoea were present. It is most likely in these patients for prolactinoma to develop after puberty, because patients have normal male body and testicular stature.

The cause of hyperprolactinemia other than prolactinoma should also be excluded. Some drugs can cause hyperprolactinemia because it is antagonistic to dopamine agonist receptors and interferes with the delivery of dopamine agonists to the portal vessels, such as metoclopramide, risperidone, domperidone, and verapamil. Patients with primary hypothyroidism may show mild hyperprolactinemia. It is alleged to be due to increased synthesis or sensitivity to the hypothalamus thyrotropin-releasing hormone that could stimulate the pituitary cells. Pregnancy increases prolactin levels up to tenfold, whereas chronic renal failure and liver disease can lead to mild hyperprolactinemia due to decreased clearance (Nassiri, 2012). The patient had no primary hypothyroidism, chronic kidney disease, or liver disease and no history of use of drugs such as antivomiting drugs, high blood pressure drugs, and psychiatric medications.

The latest clinical guide of the Endocrine Society recommends a single measurement of serum prolactin to diagnose hyperprolactinemia. Although not absolute, there is a relationship between the size of prolactinoma and increased levels of serum prolactin. If serum hyperprolactinemia is $<200$ $\mathrm{ng} / \mathrm{mL}, 80 \%$ is likely to be microprolactinoma and if $>200 \mathrm{ng} / \mathrm{mL}$, then only $20 \%$ is microprolactinoma. If the prolactin concentration increase is small then it is likely due to the compression of the pituitary stalk and the supraselic extension of the non-functional macroprolactinoma or the existence of artifacts from laboratory methods used to measure prolactin called hook effect (Gandhi, 2003; Kars et al., 2010; Ashrafuzzama, 2013).

In this patient, prolactin levels increased only by $33.07 \mathrm{ng} / \mathrm{mL}$ with cranial nerve compression signs and prolactinoma PA results were obtained, which is likely to be hyperprolactinemia due to tumor stem 
compression from non-functional macroprolactinomas. To establish the diagnosis or maternal function of the pituitary, hormones other than prolactin must be measured, i.e., TSH, LH, and Follicle Stimulating Hormone (FSH). Growth hormone may also be measured but only when deemed necessary if clinical signs of acromegaly are present. Measurement of TSH levels should be performed by measuring the levels of triiodothyronine and L-thyroxine to differentiate primary pituitary hypersecretion with the result of primary thyroid insufficiency. ACTH was determined by measurement of cortisol as one of the adrenal hormones produced by the response to adrenocorticotropin stimulation. Both cortisol and ACTH are closely related to diurnal rhythms (Gruber et al., 2012).

At the time of the patient's admission he brought laboratory results from one month before, with hyperprolactinemia, accompanied by hypo-ACTH, hypo-GH, and hypothyroidism description then it was diagnosed prolactinoma. In contrast to patients with microprolactinoma, macroprolactinoma often occurs with hypopituitarism $(45 \%)$ because other pituitary cells are compressed by tumors. Hypoputitarism is suspected when the hormone concentration of the peripheral target gland is low without increasing the associated pituitary trophic hormone levels so that serum hormone levels of $\mathrm{TSH}, \mathrm{ACTH}$, and gonadotropin may be normal or subnormal. Subdermal morning plasma cortisol levels with low or normal ACTH levels confirm a secondary hypoadrenalism (Gruber et al., 2012; Halperin Rabinovich et al., 2013).

This patient had complaints related to hypopituitarism, namely complaints of body hair thinning, easy to feel tired, not strong with cold temperatures, growth of the breasts and decreased libido. This complaint is in harmony with hormone testing which showed a decrease in all pituitary hormones other than prolactin. Although MRI is the primary choice for detecting pituitary tumors and treatment follow up as they are considered more sensitive than previous methods, namely sellar tomography and CT scans, the cost, and availability of the device are among the obstacles. Prolactinoma will be seen as a hypo-intense or iso-intense area located in the normal gland hyper-intense area of the contrast scan. This condition is the opposite of that seen in glial tumors in the cerebral parenchyma where there is a hyperintense area of the tumor and the area around the brain edema. Prolactinomas may be classified as macroprolactinomas if $<10 \mathrm{~mm}$ in diameter and macroprolactinomas if $>10 \mathrm{~mm}$ in diameter (Iglesias and Diez, 2013).

Head MSCT scans revealed lobulated cystic masses with firm borders, regular edges, measuring $3.78 \times 3.27 \times 4.04 \mathrm{~cm}$ in hypophysis, hypointense T1 appearance, and hyperintense T2 appearance, also slight enhancement after contrast injection. The mass appeared to extend to the suprasellar and suppress the optic chiasma. Thus prolactinoma in these patients is classified as macroprolactinoma.

Dopamine agonists are the main therapy for microprolactinoma and macroprolactinomas. These preparations rapidly normalize prolactin levels, restore reproductive function, and eliminate galactorrhea. In patients with macroprolactinoma, the additional purpose of dopamine agonist therapy is to reduce or stabilize tumor masses as well as to prevent neurologic complications, including headache and cranial nerve compression syndrome. Dopamine agonists include bromocriptine and cabergoline, an ergot derivative, and quinagolide. The initial dose of bromocriptine is $0.625-2.5 \mathrm{mg}$ daily with a maintenance dose of 2.5-10.0 mg daily. The initial dose of Cabergoline is $0.25-0.5 \mathrm{mg}$ every week with a range of $0.25-3.0 \mathrm{mg}$ per week for the maintenance dose. Side-effects may include gastrointestinal symptoms and orthostatic hypotension. But all can be minimized by starting treatment from very low doses and encouraging patients to take medication with food before bed at night (Klibanski, 2010). One study showed that cabergoline is better than Bromocriptine in terms of reducing prolactin levels back to normal and the incidence of adverse events, and with its rarer administration may improve patient compliance (Katznelson, 2002; Fitzgerald, 2005). However, although cabergoline is considered the best treatment option, bromocriptine remains a major therapeutic option due to drug availability and price.

The patient was given $2.5 \mathrm{mg}$ of bromocriptine daily and within ten days of a headache, and complaints decreased even though there was no improvement in vision. No side-effects were found during bromocriptine use.

In ACTH secretion disorder, a patient will need glucocorticoid replacement therapy but not mineralocorticoids. Options include acetate cortisone (12.5-25 mg morning, $12.5 \mathrm{mg}$ night), hydrocortisone (morning 10-20mg, $10 \mathrm{mg}$ night) or prednisolone (2.5-5mg morning, $2.5 \mathrm{mg}$ night). Plasma cortisol levels are not very helpful in monitoring therapy.

Initially, patients receive $5 \mathrm{mg}$ of Prednisone twice a day orally and $50 \mathrm{mcg}$ of Euthyrox once a 
day orally while waiting for scheduled neurosurgery. Prior to surgery, the dose should be given at least twice as much as steroid maintenance plus 50 dose stress of Hydrocortisone IV (equivalent dose $20 \mathrm{mg}$ of Hydrocortisone, $5 \mathrm{mg}$ of Prednisone and $0.75 \mathrm{mg}$ of Dexamethasone). In the hypothyroid state, the dose of thyroxine was the same as that of primary hypothyroidism (Halperin Rabinovich et al., 2013; Gruber et al., 2012). Since no Hydrocortison IV regimen was found, it was substituted with Dexamethasone given in pre-op and post-op of $2 \mathrm{mg}$ intravenous.

Surgical treatment is performed when a neuroophthalmological defect is seen as a progressive and rapid deterioration of vision or paralysis due to intratumoral bleeding or pituitary apoplexy, drug resistance, intolerance or lack of adherence to medical treatment and cerebrospinal fistula secondary to decreased tumor size after therapy with DA. Adenomectomy via transsphenoidal is a major surgical technique used in most cases of prolactinoma. The craniotomy is performed only for large tumors that are not accessible through conventional procedures. In contrast to macroprolactinomas in which surgery can restore prolactin concentrations up to $85-90 \%$, the macroprolactinoma number varies between $18-80 \%$. Radiation therapy is given to patients with large lesions that are unsuitable for further surgery and who have side-effects or no response to dopamine agonist therapy (Klibanski, 2010; Rotariu, 2011).

This patient underwent tumor resection surgery using the transsphenoidal technique with the indication of neuro-ophthalmology defect in the form of progressive and rapid deterioration of vision. Remission of prolactin concentration occurred from 33.07 to 19.29 postoperatively or $58 \%$ of baseline at diagnosis.

In postoperative conditions, basal hormone values are re-measured, which aims to determine whether or not a condition of hypersecretion of the remaining tumor is present and to assess the adrenal function normalization of the damaged gland during the operation. After the operation, the hormone deficit will return in $50 \%$ of patients and the rest will decrease the hormonal function of the anterior pituitary (Nassiri, 2012).

One month after surgery, the prolactin secretion decreased to a $19.29 \mathrm{ng} / \mathrm{mL}$ prolactin level but anterior pituitary secondary deficits were still found with the cortisol $1.27 \mathrm{ng} / \mathrm{ml}$ (morning: 62-194, afternoon $23-119 \mathrm{ng} / \mathrm{ml})$, TSH $0.28 \mathrm{uIU} / \mathrm{ml}(0.35$ 5.50), FT4 $0.78 \mathrm{ng} / \mathrm{dl}$ (0.89-1.76). LH examination and testosterone are awaiting results.
In general, gynecologic therapy is performed based on the specific cause. If the cause can be identified and treated during the proliferation phase, there is still the possibility of regression of breast enlargement. If gynecomastia has occurred for more than 1 year, regression is more difficult either spontaneously or with medical therapy, because fibrosis has occurred. In this condition, surgical subcutaneous or liposuction mastectomy is the best choice for cosmetic improvement (Barros and Sampaio Mde, 2012). Pharmacotherapy is effective when given early before fibrosis tissue replaces the glandular tissue. The most commonly used option of preparations is estrogen receptor modifiers (Johnson and Murad, 2009). In this patient the breasts began to appear to shrink a month after surgery. Definitive therapy will be considered according to disease progression.

The prognosis depends greatly on the functional status, size and invasive power of the tumor. A significant increase in visual acuity was reported in the first two weeks postoperatively, and then further improvement decreased after this period. The field defect significantly increased during the first two weeks postoperatively and stopped the increase after the first three months. Long-term recurrence rates are reported at $18 \%$ for microprolactinoma and $23 \%$ for macroprolactinoma.

In some cases, hypogonadism persists although prolactin has returned to normal levels, which is due to a definitive disorder of the hypothalamus of the pituitary, the destruction of pituitary gonadotrophs by pituitary tumors or by surgical removal. In this condition, the patient needs a substitution of testosterone in addition to dopamine agonist therapy. However, the provision of testosterone can stimulate the growth of pituitary tumors through aromatization to estradiol (Maggi et al., 2013).

In this patient, the postoperative 1-month left eye could not see but the right eye started to improve, although libido has not returned. Currently, the patient's development is still monitored to assess the need for additional therapy, pending the results of testosterone levels.

\section{CONCLUSIONS}

This report is of a man, 43 years old with complaints of blurry eyes, headache, decreased libido and breast growth. Hormonal examination found an increase in prolactin level accompanied by secondary hypocortisol and secondary hypothyroid. From the examination, MSCT found a macroprolactinoma. 
Surgery was performed using the transsphenoidal technique with $5 \mathrm{mg}$ of Prednisone twice a day orally, $50 \mathrm{mcg}$ of Euthyrox once a day orally and Bromocriptine with a dose of $2.5 \mathrm{mg}$. One month after surgery there was improvement of headache complaints, the level of vision and breasts looked smaller even though libido had not returned. Prolactin levels returned to normal but the patient was still hypothyroid and hypocritical but with a good prognosis with regular taking of hormone replacement drugs.

\section{REFERENCES}

ASHRAFUZZAMA, S. A. L. Z. 2013. Hyperprolactinemia. Birdem Med J, 3, 99-105.

BARROS, A. C. \& SAMPAIO MDE, C. 2012. Gynecomastia: physiopathology, evaluation and treatment. Sao Paulo Med J, 130, 187-97.

BENITEZ, M. E. A. 2009. Chronic cluster-like headache secondary to prolactinoma: uncommon cephalgia in association with brain tumors. $J$ pain symptom manage, 37, 271-6.

EDVARDSSON, B. 2013. Cluster Headache and Pituitary Prolactinoma. B J Med Cases, 4, 523-525.

FITZGERALD, P. 2005. Hiperprolactinemia, New York, Mc Graw Hill.

GANDHI, C. A. P. K. 2003. Neoplasms of the Endocrine Glands: Pituitary Neoplasms.

GRUBER, M., WILLENBERG, H. S. \& BORNSTEIN, S. R. 2012. [New developments in pituitary diseases]. Dtsch Med Wochenschr, 137, 2540-2.

HALPERIN RABINOVICH, I., CAMARA GOMEZ, R., GARCIA MOURIZ, M., OLLERO GARCIAAGULLO, D. \& GRUPO DE TRABAJO DE NEUROENDOCRINOLOGIA DE LA, S. 2013. [Clinical guidelines for diagnosis and treatment of prolactinoma and hyperprolactinemia]. Endocrinol Nutr, 60, 308-19.

IGLESIAS, P. \& DIEZ, J. J. 2013. Macroprolactinoma: a diagnostic and therapeutic update. QJM, 106, 495-504.

JOHNSON, R. E. \& MURAD, M. H. 2009. Gynecomastia: pathophysiology, evaluation, and management. Mayo Clin Proc, 84, 1010-5.

KARS, M., DEKKERS, O. M., PEREIRA, A. M. \& ROMIJN, J. A. 2010. Update in prolactinomas. Neth J Med, 68, 104-12.

KATZNELSON, L. A. K. A. 2002. Prolactin and its disorders., Lippincott Williams \& Wilkins Publishers.

KLIBANSKI, A. 2010. Clinical practice. Prolactinomas. $N$ Engl J Med, 362, 1219-26.

LEVIN, V., LEIBEL SA, GUTIN PH 2001. Pituitary adenomas. In: Principles and Practice of Oncology 6th edition, Lippincott Williams \& Wilkins Publishers.

MAGGI, M., BUVAT, J., CORONA, G., GUAY, A. \& TORRES, L. O. 2013. Hormonal causes of male sexual dysfunctions and their management (hyperprolactinemia, thyroid disorders, GH disorders, and DHEA). J Sex Med, 10, 661-77.

MELMED, S. A. J. J. 2005. Prolactin. In: Harrison's principal internal medicine. 16th edition, New York, Mc Graw Hill.

NASSIRI, F. E. A. 2012. Prolactinomas: diagnosis and treatment. Expert Rev Endocrinol Metab, 7, 233-41.

ROTARIU, D. E. A. 2011. Pituitary adenoma, therapeutic approach and surgical results. Romanian Neurosurgery, 4, 465-475.

SALAZAR-LOPEZ-ORTIZ, C. G., HERNANDEZBUENO, J. A., GONZALEZ-BARCENA, D., LOPEZ-GAMBOA, M., ORTIZ-PLATA, A., PORIAS-CUELLAR, H. L., REMBAOBOJORQUEZ, J. D., SANDOVAL-HUERTA, G. A., TAPIA-SERRANO, R., VAZQUEZ-CASTILLO, G. G. \& VITAL-REYES, V. S. 2014. [Clinical practice guideline for the diagnosis and treatment of hyperprolactinemia]. Ginecol Obstet Mex, 82, 123-42.

WASS, J. A. B. G. 2002. Pituitary tumours, In: Oxford Textbook of Oncology 2nd edition (February 2002). Oxford Press. 